\title{
INOVAÇÃO TECNOLÓGICA NA PRODUÇÃO BRASILEIRA DE SAL MARINHO E AS ALTERAÇÕES SÓCIOTERRITORIAIS DELA DECORRENTES: UMA ANÁLISE SOB A ÓTICA DA TEORIA DO EMPREENDEDORISMO DE SCHUMPETER
}

\section{Technological innovation in the production of sea salt in Brazil and changes her socio-territorial arising out: an analysis under the perspective of Schumpeter's Entrepreneurship Theory}

Marco Túlio Mendonça Diniz Universidade Federal do Rio Grande do Norte, Natal, Rio Grande do Norte, Brasil tuliogeografia@gmail.com

Fábio Perdigão Vasconcelos Universidade Estadual do Ceará, Fortaleza, Ceará, Brasil fabioperdigao@gmail.com

Márcia Barbosa Martins Universidade do Estado do Rio de Janeiro, Rio de Janeiro, Rio de Janeiro, Brasil marciabm@gmail.com

Artigo recebido em 04/12/2013 e aceito para publicação em 14/11/2015

RESUMO: A atividade salineira já foi praticada de forma extensiva em todo o litoral brasileiro desde o Pará até o Rio de Janeiro, hoje as salinas mecanizadas do litoral setentrional potiguar produzem cerca de $94 \%$ do sal marinho brasileiro. O empreendedorismo dos empresários que investiram nas salinas norte-riograndenses foi o principal responsável pela criação da atual estrutura produtiva e de comércio interno de sal marinho, na qual o Rio Grande do Norte produz a maior parte deste importante insumo à indústria e agropecuária do país. O empreendedorismo das empresas de sal potiguar foi analisado sob a ótica da Teoria de Schumpeter, uma vez que puderam ser identificados os cinco pontos fundamentais desta teoria no desenvolvimento da indústria salineira potiguar. Aproveitando-se das melhores condições naturais para a instalação da atividade, os empresários criaram um ambiente que pode potencializar artificialmente, de forma mecânica, a produtividade das salinas. As alterações na estrutura produtiva causaram também alterações na estrutura espacial das áreas dedicadas à produção de sal marinho.

Palavras-chave: Costa Semiárida do Brasil; Litoral Setentrional Potiguar; Salinas; Empreendedorismo; Relação Sociedade-Natureza.

ABSTRACT: The salt work activity has been practiced extensively throughout the Brazilian coast from Para State to the Rio de Janeiro State, today the mechanized salt industry from the Northern Rio Grande do Norte's coast produce about $94 \%$ of the Brazilian sea salt. The entrepreneurship action of the businessmen who invested in the Rio Grande do Norte's salt works was primarily responsible for the creation of the current productive structure and internal trade of sea salt, in which the Rio Grande do Norte produces most of this important input to industry and agriculture of the country. The corporate entrepreneurship of the 
Rio Grande do Norte's salt works was analyzed from the perspective of Schumpeter's theory, since they could be identified the five key points of this theory in the development of the Rio Grande do Norte's salt industry. Taking advantage of the best natural conditions for the installation activity, entrepreneurs have created an environment that can artificially boost, mechanically, the productivity of has industry. Changes in the production structure also caused changes in the spatial structure of areas dedicated to the production of sea salt.

Keywords: Brazilian Semiarid Coast; Rio Grande do Norte Northern Coast; Salt Works; Entrepreneurship; Society-Nature Relationship.

\section{INTRODUÇÃO}

O consumo de sal pelo homem é tão antigo quanto a sua história, na antiguidade há diversos relatos de sociedades que deram grande valor ao sal, segundo Souto e Fernandes (2005, p. 12) "a palavra sal origina da palavra latina salis, deusa da saúde, e transmite uma conotação de sabedoria". Os mesmos autores comentam a famosa história da construção de um caminho que ligava as salinas de Óstia a Roma na Itália por volta de 500 anos antes de Cristo, chamado Via Salária. O caminho por onde passava o valioso produto era guardado por soldados romanos, que recebiam parte de seu pagamento em sal, ao qual denominavam salarium, o que teria originado o sistema salarial utilizado até os dias de hoje.

No Brasil a produção e consumo de sal é pré-colonial, sabe-se que aqui havia salinas naturais (onde o sal se acumulava naturalmente) desde antes da invasão por povos europeus, especialmente no Nordeste do país. Após a colonização, as grandes salinas do Nordeste setentrional foram descobertas pelos portugueses quando esses rumaram para o Maranhão em sua disputa com os franceses por trechos da colônia. Em 1587, "Gabriel Soares de Souza, ao descrever a costa brasileira, salientava que no Rio Grande havia muito sal feito" (ANDRADE, 1995, p. 23), Nesse primeiro registro, é possível observar que nessas terras o sal "coalhava", naturalmente, nas salinas.

Os portugueses que colonizaram o Nordeste construíram salinas pequenas na desembocadura de rios para a extração do sal marinho, esse era utilizado na arte de curtir couros e na salga de carnes e peixes, visando a sua conserva e logo se tornaram conhecidas as salinas de Itamaracá em Pernambuco e de Serigi no Sergipe, as quais tinham uma considerável expressão local (ANDRADE, 1995).

Além das salinas do Nordeste, havia atividade salineira importante também no entorno da Lagoa de Araruama, uma laguna de alta salinidade localizada na Região dos Lagos Fluminense. Lá, como no restante das terras do Brasil Colonial, até o ano de 1631 a produção e o comércio de sal eram livres. O sal era transportado como lastro de embarcações que vinham de Portugal em busca de açúcar e outros gêneros de exportação. Mas logo os portugueses perceberam que poderiam auferir lucro em vender sal para o Brasil, já que eram grandes produtores nas marinhas de Setúbal, do Aveiro e da Figueira. Em 4 de agosto de 1631 foi estabelecido por alvará o estanque do sal, que proibia sua produção no Brasil (CHRISTÓVÃO, 2011). Após o estanque a produção salineira continuou de forma clandestina no Brasil e só veio a ser liberada oficialmente em 1801, o que retardou bastante o desenvolvimento da atividade no Brasil.

Com a vinda da família real portuguesa para o Brasil, em carta Régia de 7 de setembro de 1808, Dom João VI determinou e incentivou a exploração das salinas brasileiras (CARVALHO JÚNIOR; FELIPE; ESCÓSSIA, 1982), já que a indústria de sal portuguesa caíra em domínio napoleônico (SOUTO; FERNANDES, 2005) e então houve escassez de sal em todo o Reino (GIFFONI, 1999). Com a transformação do Brasil, ou pelo menos, do Rio de Janeiro em sede da Coroa Portuguesa, o interesse em produzir sal, localmente, passou a ser uma necessidade para o abastecimento do reino.

Mesmo com os incentivos a produção de sal marinho do Brasil não pode atender a todo o mercado nacional, pois acontecia de forma artesanal e muito dispersa no território. Neste trabalho daremos ênfase às transformações ocorridas na estrutura da produção 
e comércio interno do sal marinho, especialmente na fase de grandes transformações dessa estrutura ocorrida entre as décadas de 1960 e 1970 do século XX.

\section{AS MUDANÇAS OCORRIDAS NA ESTRUTURA DE PRODUÇÃO E COMÉRCIO INTERNO DE SAL MARINHO NO BRASIL A PARTIR DO SÉCULO XX}

No início do Século XX o sal era produzido em todos os estados litorâneos desde o Pará até o Rio de Janeiro, na grande maioria, a produção desses estados se dedicava ao abastecimento local de parte de sua população urbana, especialmente nas capitais, e nas zonas rurais mais próximas das salinas. Ainda assim o Brasil era importador de sal, isto era um empecilho ao desenvolvimento da indústria nacional, uma vez que além do consumo humano, o sal é um elemento basal para vários setores industriais como a indústria química e de petróleo que estava por florescer no Brasil.

Durante o Estado Novo foram criados vários institutos com vias a reorganizar a economia nacional e a proteger os produtos nacionais de concorrentes importados (ANDRADE, 1995). Um dos institutos criados foi o Instituto Nacional do Sal (INS) pelo Decreto-Lei No 2.300, de 6 de julho de 1940, com jurisdição em todo território nacional. Dentre outras atribuiçõeso INS foi responsável pelo estabelecimento de cotas para os estados produtores e financiamento da produção; o INS vedou a construção e ampliação de novas salinas e racionalizou a relação entre produção e consumo. Em um primeiro momento este protecionismo foi benéfico, já que garantia mercado para o desenvolvimento da atividade salineira, mas posteriormente as cotas limitaram o desenvolvimento desta mesma atividade em determinados estados.

No ano de 1957 o INS passa a se chamar Instituto Brasileiro do Sal (IBS), porém, na prática nada muda, porque permanecem as cotas, assim como as reclamações por parte dos produtores em relação às mesmas, até que em 1967, o IBS deixa de existir, e em seu lugar é criada a Comissão Executiva do Sal (CES), através do Decreto-lei ${ }^{\circ}$ 257 de 28 de fevereiro de 1967. Quatro meses após sua criação, a CES extingue o sistema de cotas. Essa ação era temida por alguns produtores, pois liberava o comércio de sal bem como a ampliação e venda de salinas, o que certamente viria a favorecer ao grande capital monopolista (CHRISTÓVÃO, 2011).

O fim das cotas possibilitava a ampliação da produção de sal em uma vasta área ociosa, principalmente no Rio Grande do Norte, desde que fossem feitos os devidos investimentos em ampliação das salinas e melhorias no transporte. A ampliação das salinas fluminenses por sua vez, era impossível já que estas estavam limitadas ao entorno da Lagoa de Araruama, que se encontra presa entre os morros cristalinos e a restinga, não havendo como ampliar a área para produção de sal no Rio de Janeiro. Segundo Barbiére (1975) o Estado do Rio de Janeiro tinha condições climáticas menos favoráveis que as do Rio Grande do Norte para a produção de sal marinho, contudo o maior preço do frete do sal potiguar em relação ao sal fluminense proporcionava maiores lucros aos produtores do Rio de Janeiro, enquanto que limitava o crescimento da economia salineira potiguar.

Até a construção do Terminal Salineiro de Areia Branca - TERMISA, ou Porto-Iha de Areia Branca (Figura 1) no Rio Grande do Norte, localizado a cerca de $14 \mathrm{~km}$ da costa da cidade de Areia Branca, em 1974, o sal potiguar era levado de barcaça das salinas até navios ancorados em alto mar. Femenick (2007, online) faz uma descrição do quanto era complicado, demorado, e por consequência, custoso, o transporte do sal potiguar antes da construção do Porto-Ilha de Areia Branca:

Depois de carregadas, as barcaças transportavam o sal até o costado do navio, às vezes percorrendo 15 milhas, até o mar aberto. O tempo de duração das viagens, entre as salinas e o costado dos navios, era de seis a oito horas para as barcaças a vela ou rebocadas; e de cerca de duas horas, para as autopropulsadas. Ai começava outra operação também precária e ineficiente: $\mathrm{o}$ transbordo da carga das barcaças para os navios. O sal era transferido em tinas que tinham capacidade entre 400 e 700 quilos, enchidas manualmente 
nas barcaças por vários estivadores e levado para os porões dos navios por operadores de guinchos. O processo, agravado pelas difíceis condições de trabalho a descoberto em alto mar, limitava bastante a capacidade de escoamento de sal da região, além de ser a causa principal da grande elevação dos custos de transporte. De fato, um navio do tipo Liberty, de 10.000 DWT (Deadweight - peso de carga), demorava, em média, 15 dias carregando, a um ritmo de menos de 800 toneladas por dia.

Figura 1 - Vista área e panorâmica do Porto-Ilha de Areia Branca

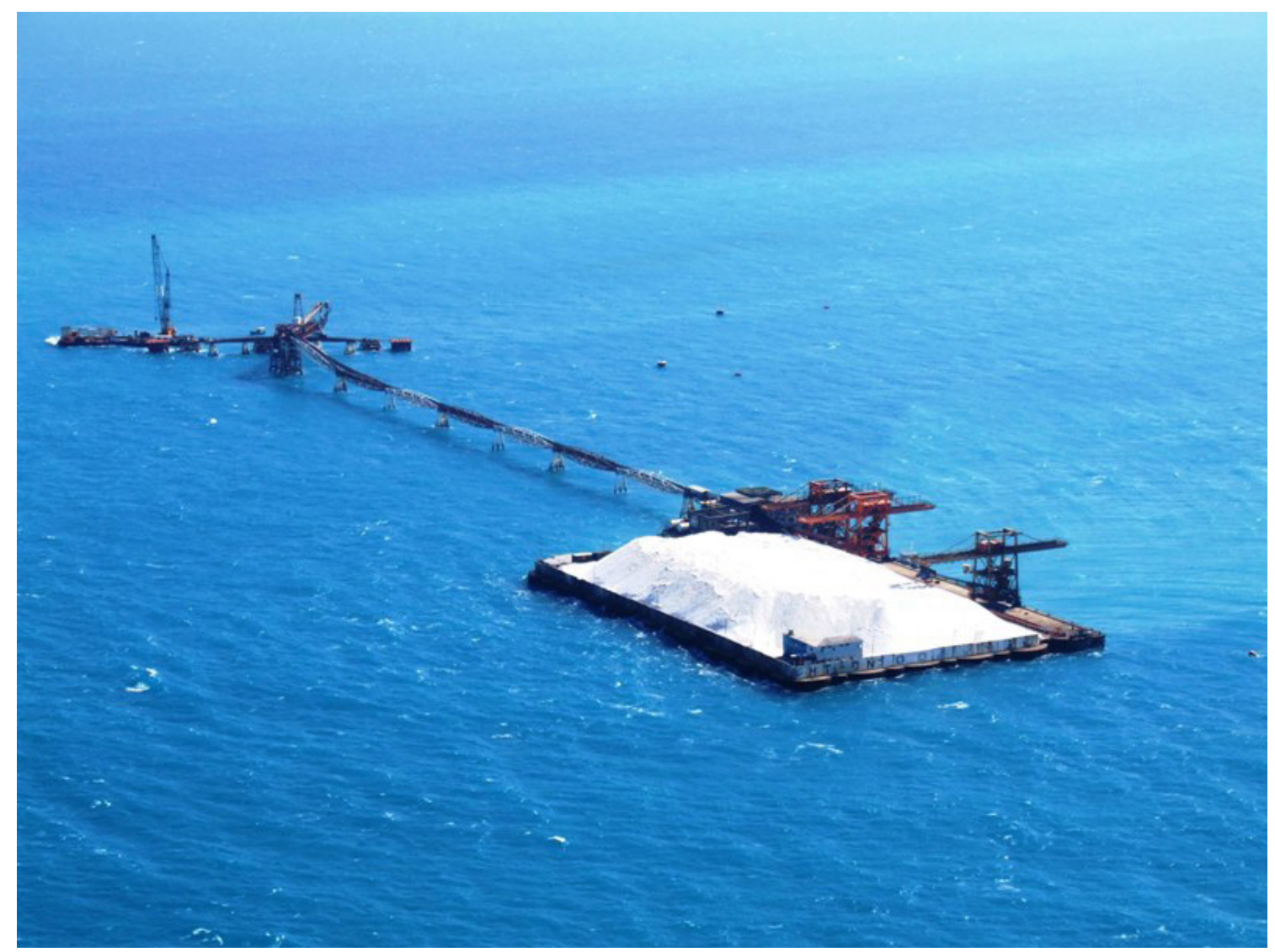

Fonte: CONSTREMAC Construções, 2010.

Além dos problemas de transporte, o pouco desenvolvimento tecnológico da atividade era outro empecilho, a indústria salineira do Rio Grande do Norte funcionou de forma artesanal até fins dos anos 1960, usando mão-de-obra de forma extensiva e em condições precárias (Figura 2, imagem A), mas após o fim das cotas em 1967 a atividade salineira se modernizou no Rio Grande do Norte, as salinas artesanais foram pouco a pouco sendo adquiridas por empresas estrangeiras que industrializaram (mecanizaram) sua produção (Figura 2, imagens B e C). 
Figura 2- Mosaico de imagens de salinas.

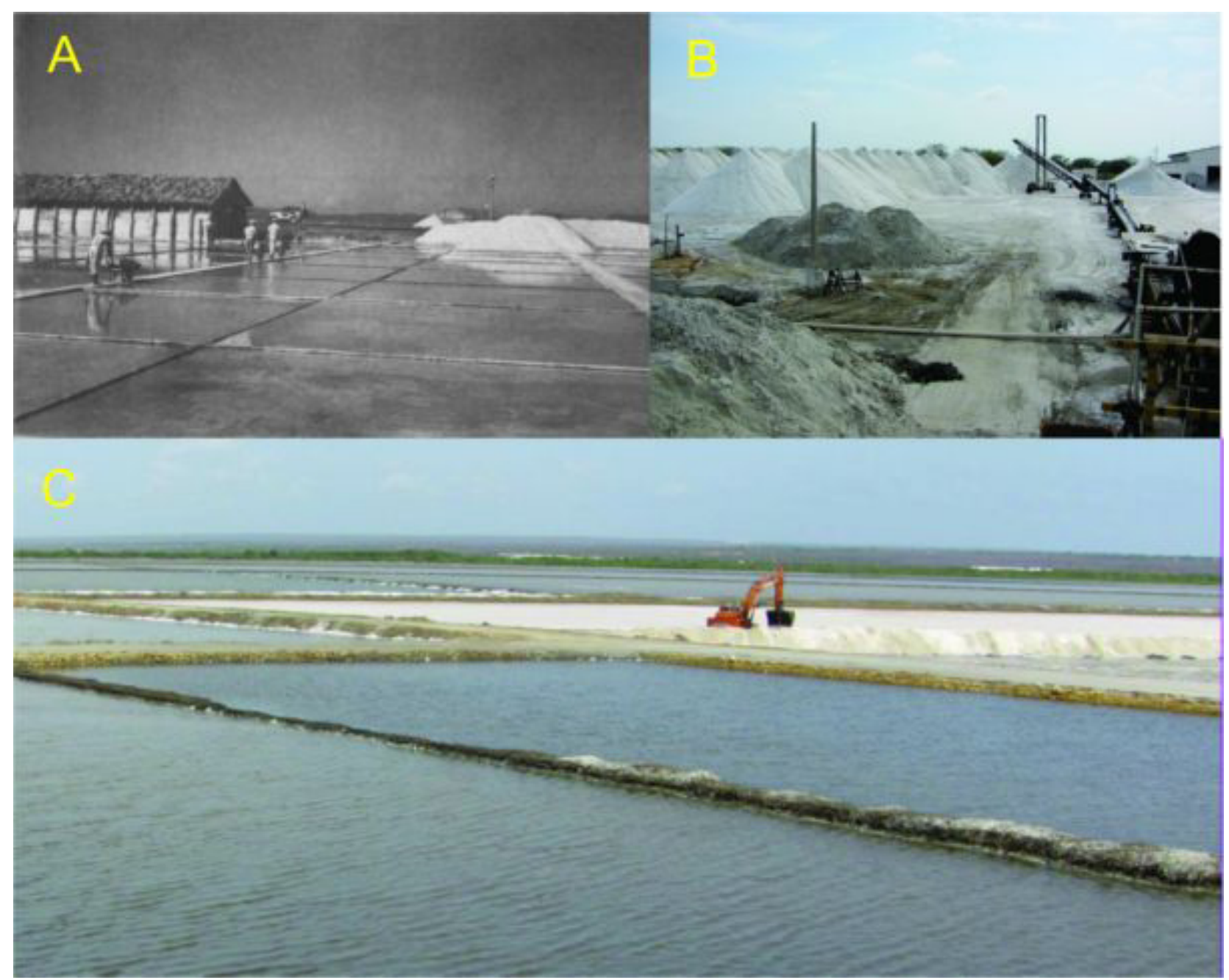

(A) Salina artesanal perto da cidade de Araruama/RJ em 1958, atualmente nesta área o método de extração de sal continua o mesmo; (B) Armazenamento de sal em "pirâmides" por esteira empilhadeira em salina mecanizada próximo à cidade de Grossos/ RN, em fevereiro de 2012; (C) Colhedeira retirando espessa camada de sal em tanque evaporador, salina mecanizada próximo à cidade de Grossos/RN, em fevereiro de 2012.

Fonte: "Imagem A" de Antônio Teixeira Guerra e Tibor Jablonsky no ano de 1958, "Imagens B e C" dos autores em atividade de campo em novembro de 2012

Apenas a partir do ano de 1938 no Anuário Estatístico do Brasil, editado pelo Instituto Brasileiro de Geografia e Estatística - IBGE, passou a constar dados da produção brasileira de sal, os números para aquele ano são completamente diferentes dos registrados atualmente, especialmente em um estado - o Rio Grande do Norte (Quadro 1): 
Quadro 1 - Produção brasileira de sal marinho em toneladas (t) e percentual (\%) por unidades da federação (UF) os anos de 1938 e 2013

\begin{tabular}{|c|c|c|c|c|}
\hline \multicolumn{5}{|c|}{ PRODUÇÃO DE SAL MARINHO NO BRASIL } \\
\hline \multirow{2}{*}{ UF } & \multicolumn{2}{|l|}{1938} & \multicolumn{2}{|l|}{2013} \\
\hline & $\mathrm{t}$ & $\%$ & $\mathrm{t}$ & $\%$ \\
\hline $\mathrm{PA}^{*}$ & --- & --- & --- & --- \\
\hline MA & 18.145 & 2,40 & --- & --- \\
\hline PI & 5.000 & 0,66 & 8.000 & 0,1 \\
\hline $\mathrm{CE}$ & 42.756 & 5,66 & 108.000 & 1,5 \\
\hline RN & 549.494 & 72,79 & 5.589 .000 & 94,5 \\
\hline PB & 3.057 & 0,40 & --- & --- \\
\hline PE & 4.757 & 0,63 & --- & --- \\
\hline $\mathrm{AL}$ & 1.086 & 0,14 & --- & --- \\
\hline SE & 38.263 & 5,06 & --- & --- \\
\hline $\mathrm{BA}$ & 9.458 & 1,25 & --- & --- \\
\hline ES & 62 & 0,01 & --- & --- \\
\hline RJ & 82.793 & 10,96 & 206.000 & 2,9 \\
\hline BRASIL & 754.871 & 100 & 5.911 .000 & 100 \\
\hline
\end{tabular}

Fonte: Anuário Estatístico do Brasil - 1953 e Sumário Mineral Brasileiro ano de 2014.

*A produção de sal marinho no Pará só foi registrada oficialmente a partir de 1944.

Na análise do Quadro1 é possível perceber que em 1938 dos três maiores produtores de sal marinho, dois eram do Nordeste setentrional, Ceará e Rio Grande do Norte; e o outro era o Rio de Janeiro. Atualmente estes continuam a ser os maiores produtores de sal marinho (o outro único estado onde ainda se produz sal marinho é o Piauí), entretanto, enquanto que em 2013 a produção de sal marinho nos Estados do Ceará e Rio de Janeiro cresceu pouco mais de duas vezes em relação a 1938, no maior produtor - o Rio Grande do Norte - esta produção cresceu mais de dez vezes no mesmo período.

Outro fato interessante revelado pelos dados é que a produção de sal marinho que já fora registrada em 12 estados brasileiros, atualmente ocorre em apenas quatro deles, sendo que se concentra em cerca de 94\% no Estado do Rio Grande do Norte.
Esta condição quase que monopólica estabelecida pelo estado potiguar começou a ser construído entre fins dos anos 1960 e início dos 1970 como pode ser constatado ao compararmos a Figura 4 e a Figura 5 que retratam a produção dos três principais estados produtores. Na Figura 3 podemos visualizar as áreas onde ainda é produzido sal marinho, com especial destaque para a Costa Semiárida Brasileira, no Nordeste setentrional. 
Figura 3- Localização das principais áreas produtoras de sal marinho no Brasil

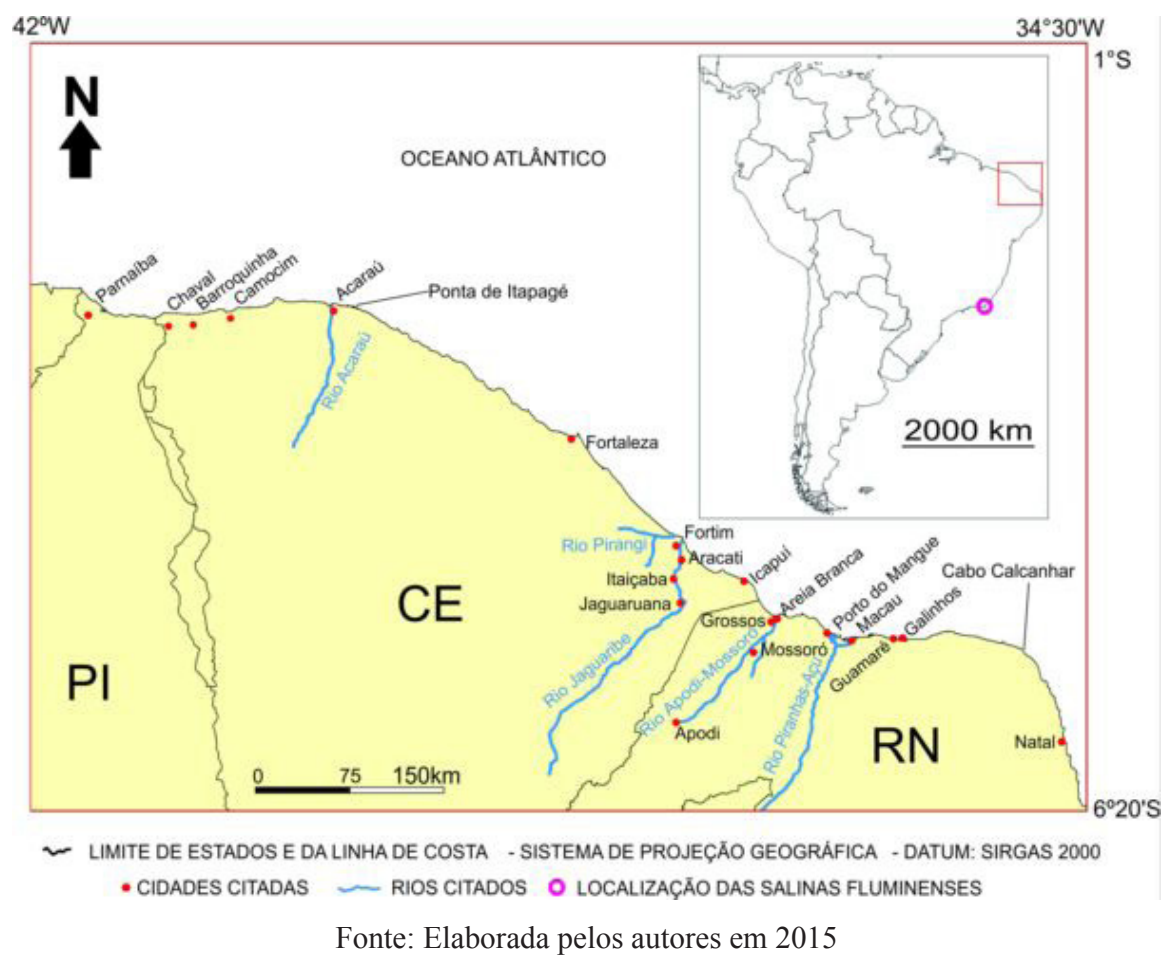

$\mathrm{Na}$ Figura 4 é possível observar que a produção de sal marinho tem uma tendência geral de crescimento nos três maiores estados produtores entre os anos de 1938 e 1970. Ao analisar a Figura 5 pode ser constatado que a partir do ano de 1975 apenas a economia salineira do Rio Grande do Norte pode verificar crescimento contínuo, enquanto que a produção de sal marinho do Ceará entrou em declínio a partir de 1971, já que em 1970 a produção cearense teve seu ápice com 270.486 toneladas e logo após decaiu. O mesmo aconteceu com a produção do Rio de Janeiro a partir de 1975, um ano após a construção do porto de Areia Branca no Rio Grande do Norte, em 1974 foram produzidas 484.741 toneladas, verificando logo após um declínio, com pequena recuperação em 1977 quando as salinas fluminenses produziram o máximo de 485.211 toneladas de sal marinho para logo no ano seguinte declinar ano a ano até os números de hoje, exceto pequenas oscilações positivas pontuais (Quadro 1). 
Figura 4 - Produção brasileira de sal marinho em toneladas (t) nos três maiores estados produtores: Rio de Janeiro (RJ); Ceará (CE); e Rio Grande do Norte (RN) entre os anos de 1938 e 1970.

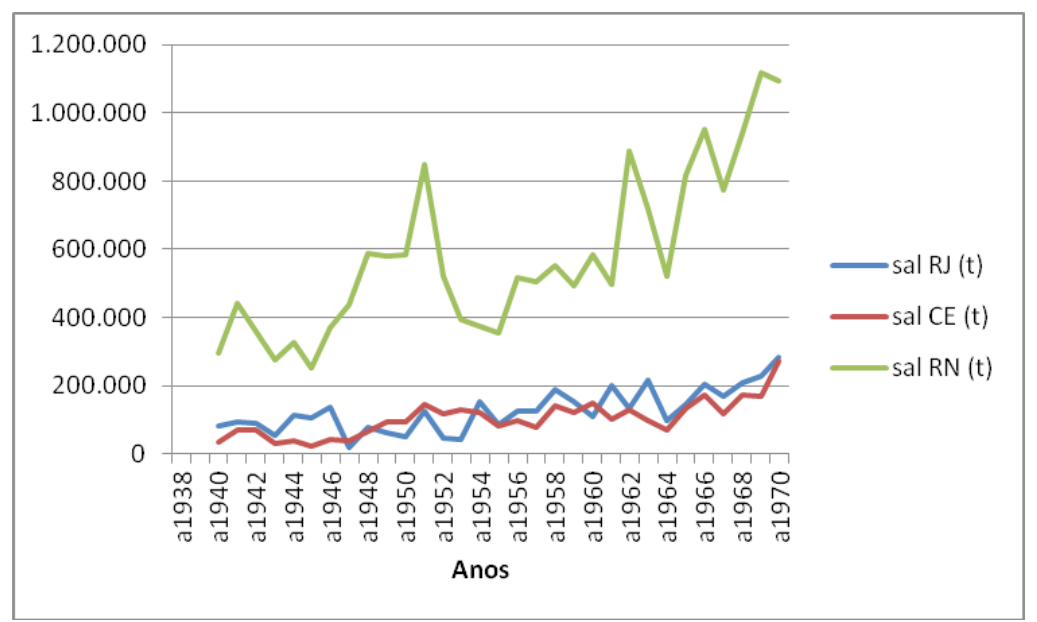

Fonte: Anuário Estatístico do Brasil - Anos de1941/1945, 1946, 1947, 1949, 1951, 1953, 1954, 1955, 1957, 1960, 1961, 1963, 1966, 1969 e 1972.

O reflexo do desenvolvimento industrial das salinas do Rio Grane do Norte atingiu todo o mercado e consumo do produto no Brasil. Após este desenvolvimento muitas salinas foram fechadas por não poderem concorrer com o produto mais barato e de melhor qualidade produzido no Rio Grande do Norte e comercializado em todo o Brasil. Além do declínio das economias salineiras de Ceará e Rio de Janeiro, a economia salineira do Piauí também declinou a partir dos anos 1970, sua produção hoje é semelhante ao que era produzido em 1938. O impacto foi ainda maior nos demais estados produtores, onde foram completamente extintas as salinas.

Figura 5 - Produção brasileira de sal marinho em toneladas $(\mathrm{t})$ nos três maiores estados produtores: Rio de Janeiro (RJ); Ceará (CE); e Rio Grande do Norte (RN) entre os anos de 1971 e 2013

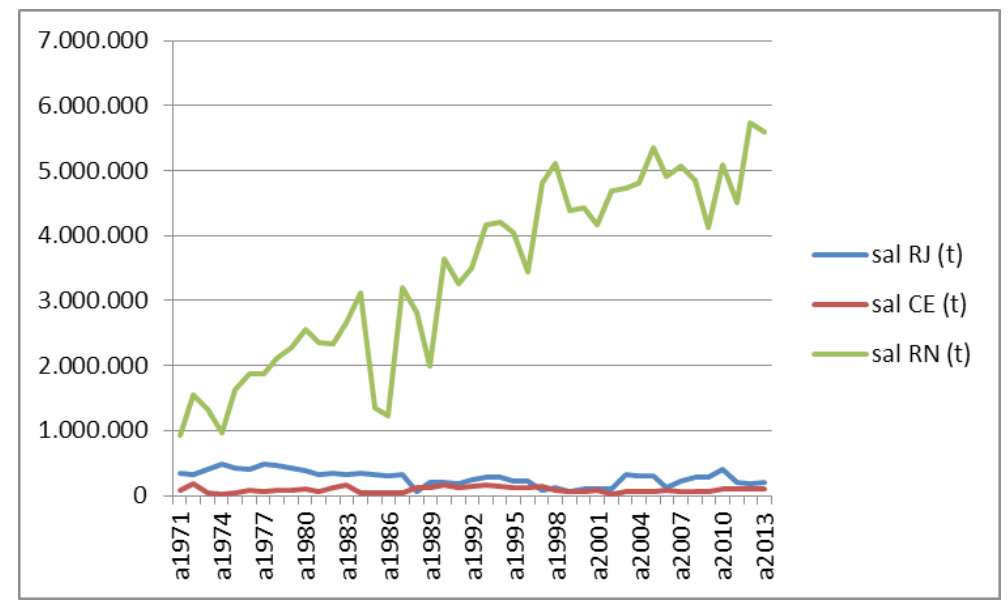

Fonte: Anuário Estatístico do Brasil - Anos de 1972, 1975, 1978, 1981, 1987/1988,

1991, 1994 e 1997; Sumário Mineral Brasileiro - anos de 1992 a 2014; e

Anuário Mineral Brasileiro anos de 1995 e 2004

Soc. \& Nat., Uberlândia, 27 (3): 421-438, set/dez/2015 
O desenvolvimento da indústria salineira do Rio Grande do Norte foi por nós considerado fruto de uma ação empreendedora nos moldes da teoria de Schumpeter, conforme analisaremos a seguir.

\section{A TEORIA DO EMPREENDEDORISMO DE SCHUMPETER E A INOVAÇÃO TECNOLÓGICA NA PRODUÇÃO DE SAL MARINHO NO BRASIL}

A teoria do empreendedorismo tem como seu maior expoente o economista austríaco Joseph Alois Schumpeter, Professor da Universidade de Havard, nos Estados Unidos, que apresenta um instrumental teórico acerca da concorrência industriale do processo de inovação tecnológica, aspectos importantes para compreender a organização das empresas capitalistas (BRASIL; NOGUEIRA; FORTE, 2011). Essa organização se dá em vários níveis, dentre eles, o espacial.

Schumpeter (1961, p. 110) comenta que o capitalismo é "uma forma ou método de transformação econômica e não, apenas, reveste caráter estacionário, pois jamais poderia tê-lo". O autor prossegue lembrando que a vida econômica transcorre em meio natural e social que estão em constante alteração e por isso mesmo tendem a alterar a situação econômica. Essas transformações aludidas, como por exemplo, as catástrofes naturais, guerras e revoluções, dentre outros, produzem frequentemente transformações industriais, embora não sejam seu móvel principal, pois:

$\mathrm{O}$ impulso fundamental que põe e mantém em funcionamento a máquina capitalista procede dos novos bens de consumo, dos novos métodos de produção ou transporte, dos novos mercados e das novas formas de organização industrial criadas pela empresa capitalista (SCHUMPETER, 1961, p. 110).

Os elementos acima citados são os responsáveis pela expansão da produção e pela redução dos preços. O mesmo autor exemplifica:

[...] a história da aparelhagem produtiva de uma fazenda típica, desde os princípios da racionalização da rotação das colheitas, da lavra e da engorda do gado até a agricultura mecanizada dos nossos dias - juntamente com os silos e as estradas-de-ferro - é uma história de revoluções, como o é a história da indústria de ferro e aço, desde o forno de carvão vegetal até os tipos que hoje conhecemos, a história da produção da eletricidade, da roda acionada pela água à instalação moderna, ou a história dos meios de transporte, que se estende da antiga carruagem ao avião que hoje corta os céus. A abertura de novos mercados, estrangeiros e domésticos, e a organização da produção, da oficina do artesão a firmas, como a U.S. Steel, servem de exemplo do mesmo processo de mutação industrial — se é que podemos usar esse termo biológico - que revoluciona incessantemente a estrutura econômica a partir de dentro, destruindo incessantemente o antigo e criando elementos novos (SCHUMPETER, 1961, p. 110 , grifos do autor).

Este processo, denominado por Schumpeter de "destruição criadora", segundo o autor é basal para compreender o sistema capitalista. O autor afirma ainda que "é dele que se constitui o capitalismo e a ele deve se adaptar toda a empresa capitalista para sobreviver" (SCHUMPETER, 1961, p. 110).

Mesmo a teoria schumpeteriana tendo sido elaborada em meados do século XX, ela continua a ter um caráter bastante atual, pois:

[...] as inovações no sistema econômico não aparecem, via de regra, de tal maneira que primeiramente as novas necessidades surgem espontaneamente nos consumidores e então o aparato produtivo se modifica sob sua pressão. Não negamos a presença desse nexo. Entretanto, é o produtor que, via de regra, inicia a mudança econômica, e os consumidores são educados por ele, se necessário; são, por assim dizer, ensinados a querer coisas novas, ou coisas que diferem em um aspecto ou outro daquelas que tinham 
o hábito de usar (SCHUMPETER, 1997, p. 76 [1964]).

Essa consideração é extremamente atual, consideremos, por exemplo, a infinidade de bens de consumo eletrônicos, projetados por processos cada vez mais inovadores, os quais vêm a satisfazer necessidades "criadas" para os consumidores do mundo contemporâneo, que vêm sendo diuturnamente "educados" pelas estratégias de propaganda arquitetadas pelas empresas capitalistas, as quais incentivam a adquirirem novos produtos (smartfones, tablets, netbooks, dentre outros), já que a criação desses é uma das molas mestres do sistema capitalista.

A destruição criadora de Schumpeter é o que ele considera como sendo desenvolvimento:

O desenvolvimento, no sentido que lhe damos, é definido então pela realização de novas combinações. Esse conceito engloba os cinco casos seguintes: 1) Introdução de um novo bem - ou seja, um bem com que os consumidores ainda não estiverem familiarizados - ou de uma nova qualidade de um bem. 2) Introdução de um novo método de produção, ou seja, um método que ainda não tenha sido testado pela experiência no ramo próprio da indústria de transformação, que de modo algum precisa ser baseada numa descoberta cientificamente nova, e pode consistir também em nova maneira de manejar comercialmente uma mercadoria. 3) abertura de um novo mercado, ou seja, de um mercado em que o ramo particular da indústria de transformação do país em questão não tenha ainda entrado, quer esse mercado tenha existido antes, quer não. 4) Conquista de uma nova fonte de oferta de matériasprimas ou de bens semimanufaturados, mais uma vez independentemente do fato de que essa fonte já existia ou teve que ser criada. 5) Estabelecimento de uma nova organização de qualquer indústria, como a criação de uma posição de monopólio (por exemplo, pela trustificação) ou a fragmentação de uma posição de monopólio (SCUMPETER, 1997, p. 77 [1964], grifos nossos).

A história das salinas potiguares nos últimos cinquenta anos, e de como os produtores do Rio Grande do Norte conseguiram alcançar o estágio atual, no qual produzem mais de $90 \%$ de todo o sal marinho do Brasil, é uma história de destruição criadora e de desenvolvimento econômico nos moldes apresentados por Schumpeter.

Vejamos os cinco casos da teoria schumperiana aplicados à economia salineira potiguar:

1) O sal é um bem necessário ao homem que tem seu uso conhecido desde a antiguidade, sendo esse uso quase tão antigo quanto os primeiros registros históricos. Dessa forma, não haveria para os produtores como oferecer um novo produto em si, mas esses puderam ao longo dos anos melhorar sua qualidade e variedade através de novos processos de produção e embalagem que vão desde embalagens de $1 \mathrm{~g}$ até sacos de $50 \mathrm{~kg}$, ou mesmo não embalado, conforme o tipo de cliente que pode ser um restaurante ou uma indústria petroquímica; ou ainda com produtos como o sal light que tem a metade do sódio do sal comum visando clientes portadores de doenças que exigem dieta hipossódica. Esse tipo de inovação se dá sempre no sentido de buscar atender uma gama cada vez maior de consumidores. Assim os produtores potiguares puderam criar novas qualidades de um bem com os novos processos de embalagem e refinamento da produção.

2) O Rio Grande do Norte, graças, principalmente, à natureza das planícies flúviomarinhas dos Rios Mossoró e Açu, que são bastantes largas, chegando em vários trechos a passar dos 10 quilômetros de largura, ofereceu aos produtores a possibilidade de mecanizar sua produção. Nesses vastos terrenos, é possível se ter evaporadores e cristalizadores com áreas superiores aos dois quilômetros quadrados, por onde podem transitar colhedeiras e onde podem ser instaladas esteiras mecânicas. Vale a pena ressaltar que a mecanização da produção foi a principal inovação tecnológica iniciada na década de 1960 que alterou completamente os métodos de produção.

A inovação tecnológica demandou consideráveis investimentos que vieram em parte 
de capital internacional, e parte nacional, de empresários norte-rio-grandenses e fluminenses, principalmente. Tais investimentos se justificaram graças à possibilidade de se ter grandes salinas, que, além de extensas, deram boa margem de lucro aos empresários dada a alta produtividade, que por sua vez, é proporcionada, em primeiro lugar, pelas condições naturais, e posteriormente, pela própria modernização do sistema produtivo e inovação dos métodos de produção.

3) Com a construção do Porto-Ilha de Areia Branca, no início dos anos 1970, o Rio Grande do Norte pôde entregar seu produto de melhor qualidade e com preços mais baixos em todo o país e, posteriormente, no exterior. Também nos anos que se seguiram à década de 1970, a melhoria do sistema rodoviário facilitou a abertura de novos mercados para o sal potiguar que chegou a responder por mais de $90 \%$ da produção e do consumo de sal marinho no país a partir da década de 1990 (DNPM, 1997).

4) Os grandes empresários das salinas do Rio Grande do Norte puderam, graças à disponibilidade de capital que acumularam, investir em outras áreas com potencial de produção além das áreas mais tradicionais que são os estuários dos rios Mossoró e Açu. Após a aquisição de salinas menores e ocupação quase completa das planícies dos rios Mossoró e Açu por salinas modernas, foram mecanizadas também as salinas das planícies de maré, presentes em alguns setores de seu litoral como em Galinhos e Guamaré, e do litoral cearense como no município de Icapuí (salinas pertencentes a empresas potiguares). A produção dessas novas salinas utiliza as mesmas técnicas de extração e beneficiamento; utiliza também a mesma logística de distribuição das salinas das duas grandes desembocaduras de rios do litoral setentrional potiguar. Dessa forma, aproveitando a estrutura criada, os grandes empresários puderam encontrar novas fontes de insumos para aumentar sua produção. Hoje as poucas salinas existentes no Ceará estão ligadas a empresas norte-rio-grandenses e as salinas artesanais foram praticamente extintas na região, e suas áreas foram incorporadas pelas grandes empresas do setor.

5) O sindicato dos produtores de sal do Rio Grande do Norte-SIESAL-RN é hoje na verdade um oligopólio, no qual os produtores têm a oportunidade de controlar o preço e quase toda a comercialização de sal na maior parte do território nacional. A organização em forma de oligopólio dos produtores de sal do Rio Grande do Norte se iniciou ainda nos anos 1970, quando começaram a dominar o mercado de sal no país.

Dessa forma, os cinco pontos fundamentais do processo de "destruição criadora" de Schumpeter explicam a forma pela qual se desenvolveu de forma excepcional a economia salineira potiguar. Foram destruídas as velhas estruturas das salinas artesanais, onde havia uso excessivo de mão-de-obra em condições péssimas de trabalho, e criadas as novas e modernas estruturas produtivas mecanizadas que demandam muito menos mão-de-obra, sendo essa, obrigatoriamente, de melhor qualificação técnica.

Vale a pena ressaltar o fato curioso do depoimento em informação verbal colhida em entrevista concedida pelo presidente do SIESAL/ RN na cidade de Mossoró, em fevereiro de 2012, que nos afirmou que os constantes conflitos com os trabalhadores braçais, que reivindicavam melhores salários e condições de trabalho e renda, foram uns dos principais responsáveis pelos investimentos que vieram a aumentar grandemente a produtividade das empresas, gerando junto a isso grande desemprego nas cidades de Macau, Areia Branca e Mossoró, na época da transição das salinas artesanais para as mecanizadas.

$\mathrm{Na}$ leitura que Brasil, Nogueira, e Forte (2011) fizeram da obra de Schumpeter está dito que o processo de inovação tecnológica desse autor é considerado endógeno ao sistema econômico, e que ocorreria em três fases distintas e complementares: invenção, inovação e difusão. Os autores prosseguem em sua análise explicando que:

Primeiramente, a fase de invenção se dá quando novos produtos e ou processos produtivos são criados. À medida que essas inovações tecnológicas são introduzidas no sistema econômico, então, ocorre a fase de inovação propriamente dita. Quando o empresário empreendedor adota uma inovação tecnológica, ele obtém um diferencial competitivo, que se dá principalmente sob 
a forma de reduções dos seus custos de produção e ou de diferenciação de produtos, em relação às demais empresas concorrentes de um determinado mercado, o que lhe confere uma maior autonomia para determinar os seus preços. E isso acontece de acordo com a natureza da inovação introduzida. Assim, as empresas concorrentes buscam reverter essa situação desfavorável, por meio da tentativa de desenvolver novas tecnologias ou de lançar novos produtos, ou seja, com a tentativa de copiar as criações desenvolvidas pela empresa inovadora. Entretanto, deve-se ressaltar que nem todas as empresas concorrentes são capazes de acompanhar o ritmo do processo de criação das empresas inovadoras. Portanto, os mecanismos de mercado abordados nesta análise, que delineiam a concorrência schumpeteriana, atuam para selecionar as empresas mais eficientes e mais lucrativas, expulsando os competidores que utilizam processos antigos e menos eficientes, ou seja, esse é basicamente um processo no qual resultam vencedores e perdedores (BRASIL; NOGUEIRA; FORTE, 2011, p. 41-42)

Logo após, tem-se o processo de difusão entre as empresas que "sobrevivem" ao ciclo, entretanto esse processo é dinâmico, logo aparecem novos produtos e/ou processos de produção, o que reinaugura o ciclo (BRASIL; NOGUEIRA; FORTE, 2011).

Nas salinas do Rio Grande do Norte e do Ceará, o processo acima descrito ocorreu no passado e prosseguiu nesses moldes. As grandes empresas compraram as pequenas salinas artesanais que não tinham condições de acompanhar os baixos preços dos grandes produtores, que reduziram muito seus custos de produção através da inovação. As poucas empresas pequenas que existem, funcionam, em sua maioria, em cooperativas que se veem quase sempre obrigadas a vender sua produção para as grandes empresas, para que essa produção possa ser beneficiada nas grandes indústrias.

Nos dias de hoje, mesmo com a difusão de muitas técnicas, o processo de inovação persiste, as maiores empresas tem, por exemplo, moedores, refinadores e torradores de sal, e podem, portanto, oferecer um produto com menor umidade e mais refinado, considerado mais valioso pelo mercado. As maiores empresas do ramo têm a ciência e a biotecnologia a seu serviço, através de consultores altamente qualificados. É possível ter um controle refinado da produção. Esse controle pode ser biológico com a introdução de microrganismos nos tanques. Após sua entrada nos tanques, esses microrganismos são controlados no intuito de dar uma melhor qualidade ao produto final. A Artemia salina é um exemplo a ser citado, esse crustáceo filtrador é um dos responsáveis pela qualidade do sal no processo de cristalização, pois pode sobreviver em alta salinidade e seu manejo se dá por especialistas contratados pelos salineiros.

Alguns elementos aqui apresentamos fazem com que o processo de inovação perdure, de forma que só as grandes empresas conseguem agregar valor de forma considerável ao sal, fazendo com que essa atividade se mantenha bastante lucrativa para eles.

Na teoria de Schumpeter, existe a ideia de que quanto maiores forem as empresas, maior será a concorrência entre elas, dado que elas tem maior capacidade de inovação e maior resistência à investida das pequenas (BRASIL; NOGUEIRA; FORTE, 2011). Via de regra, nos dias de hoje as pequenas empresas tem suas ideias compradas bem antes da difusão.

As salinas potiguares nos dias de hoje veem a necessidade de continuar a inovar, mesmo tendo oligopolizado grande parte do mercado nacional, pois o sal dos desertos chilenos tem entrado no Brasil com boa qualidade e a baixos custos, principalmente, nos estados da Região Sul do país. A importação de sal chileno representa uma ameaça à quebra do oligopólio das empresas sediadas no Rio Grande do Norte.

\section{INOVAÇÃO TECNOLÓGICA E AS MUDANÇAS NA ESTRUTURA ESPACIAL DAS ÁREAS PRODUTORAS DE SAL MARINHO}

Ao analisar o processo de destruição criadora de Schumpeter e suas repercussões espaciais, Pires (2004) afirma que os ciclos de inovação, além de gerarem nova estrutura social de acumulação (ESA), geram também nova estrutura territorial de 
acumulação (ETA), na visão do autor:

Se a estrutura econômica se altera, a base territorial também se altera. Já que a base territorial se alterou, pode-se admitir, por conseguinte que, novamente, a estrutura econômica também tende a se alterar [...] é importante lembrar que nenhum crescimento econômico se faz sem uma base territorial efetiva de desenvolvimento ou consolidação (PIRES, 2004, online).

Os fatos comentados pelo autor se manifestaram no Nordeste Brasileiro. No caso das salinas houve sérias alterações na estrutura territorial dos municípios envolvidos com a atividade salineira. Conforme Carmo Junior (2006), o fim das salinas tradicionais trouxe grande desemprego e mais pobreza para a cidade de Macau, que tinha sua economia completamente dependente dos empregos gerados pelas salinas, desde os primórdios de sua história, até a década de 1960. Segundo o mesmo autor, os bairros pobres de moradia dos salineiros passaram a miseráveis, com repercussões nos índices de violência, tendendo a acumular, espacialmente, a miséria nas periferias desta cidade.

Por outro lado, Mossoró pôde consolidar sua posição de maior economia do interior do Rio Grande do Norte, tendo sido a força política de Mossoró a principal responsável pela instalação do terminal salineiro em Areia Branca, o que favoreceu em muito às salinas de Areia Branca, Grossos e Mossoró. A área do estuário do Rio Mossoró passou a ser a maior produtora do estado, mesmo que o delta do Rio Açu ofereça maior produtividade do ponto de vista natural à atividade salineira.

Alterações na estrutura territorial de acumulação foram muito claras nos "territórios do sal" propriamente ditos, para usar o termo de Andrade (1995), os pequenos produtores foram praticamente expulsos, tendo sido obrigados a vender suas salinas às grandes firmas, que graças ao processo de inovação podiam vender sal marinho a preços bem menores, com os quais, os que não tiveram recursos para incorporar as inovações no sistema produtivo, jamais poderiam concorrer.
Além das alterações territoriais, a paisagem das planícies flúvio-marinhas e de maré do Rio Grande do Norte, Ceará, Maranhão e Piauí foram bastante modificadas nos últimos anos. As áreas antes dedicadas à produção de sal, e que foram abandonas nas três ultimas décadas, hoje têm seus manguezais bastante recuperados, como na laguna (lagamar) do Iguape no Município de Aquiraz no Estado do Ceará (DINIZ, 2008). Antigas salinas do Ceará foram convertidas em fazendas de camarão nas décadas de 1980 e 1990, atividade que se apresentou bastante rentável nas desembocaduras dos rios cearenses, principalmente nos anos 1990. Nos dias de hoje, o Ceará é o maior produtor de camarão do Brasil.

Entretanto, no Rio Grande do Norte o que se observa é que algumas áreas de vegetação natural de mangue, e principalmente, os apicuns (ecossistemas de áreas alagadiças, inundadas em marés de sizígia e colonizados por gramíneas tolerantes à alta salinidade dos solos) que já ocuparam vastas áreas das planícies mencionadas, hoje se encontram muito reduzidas em relação à proporção espacial que já ocuparam (BARROS; SANTOS, 2010), em que pese o fato de que o ecossistema manguezal jamais tomou grandes áreas nas planícies hipersalinas do litoral setentrional potiguar.

As salinas ocupam, hoje, a grande maioria dessas terras alagadiças, que apresentam uma paisagem completamente diferente do que eram naturalmente, ou mesmo em relação às áreas que foram naturalmente recuperadas em terras cearenses, por exemplo.

No Estado do Rio de Janeiro também foram grandes as transformações espaciais decorrentes da implantação e do declínio da atividade salineira. Cabe aqui o exemplo das transformações sofridas por municípios como Cabo Frio que, historicamente, teve sua ocupação relacionada a atividade salineira e que após o declínio dessa atividade, fruto da concorrência da indústria potiguar, presenciou diversas transformações espaciais em uma área que hoje é mais um "espaço turístico" que um "espaço salineiro", onde as terras valem mais pela especulação imobiliária que do que pelo que nela se produz (CHRISTOVÃO, 2011). 


\section{CONSIDERAÇÕES FINAIS}

A atividade salineira que já foi praticada de forma extensiva em todo o litoral brasileiro desde o Pará até o Rio de Janeiro, hoje é dominada pela atividade das salinas mecanizadas do litoral setentrional potiguar, onde são produzidos cerca de 94\% do sal marinho brasileiro.

A ação empreendedora dos empresários que investiram nas salinas norte-rio-grandenses foi a principal responsável pela criação da atual estrutura produtiva e de comércio interno de sal marinho, na qual o Rio Grande do Norte produz a maior parte deste importante insumo à indústria e agropecuária do país.

O empreendedorismo das empresas de sal potiguar foi analisado sob a ótica da Teoria de Schumpeter, uma vez que puderam ser identificados os cinco pontos fundamentais desta teoria no desenvolvimento da indústria salineira potiguar. Aproveitando-se das melhores condições naturais para a instalação da atividade, os empresários criaram um ambiente que pode potencializar artificialmente, através da mecanização, a produtividade das salinas, de modo que puderam praticamente eliminar a concorrência de indústrias de fora do Rio Grande do Norte.

As alterações na estrutura produtiva causaram também alterações na estrutura espacial das áreas dedicadas à produção de sal marinho. As antigas salinas artesanais do Rio Grande do Norte foram convertidas quase todas em salinas mecanizadas, e a as salinas artesanais de outros estados foram quase todas fechadas devido à concorrência das empresas potiguares que após a construção do Porto-Ilha de Areia Branca pôde entregar seu sal mais barato e de melhor qualidade em todo o país.

Ações como as que foram implementadas no Rio Grande do Norte, analisadas no presente trabalho, devem ser buscadas de forma incessantes por empresários do setor produtivo. Essas ações devem contar ainda com a indução do estado, pois, especialmente no Nordeste do Brasil, o setor produtivo industrial, em geral, tem tecnologia bastante defasada e baixa competitividade no mercado nacional e internacional. A teoria de Schumpeter mostra que a destruição criadora, a inovação e o empreendedorismo são chaves fundamentais para o desenvolvimento empresarial em mercados cada vez mais competitivos no sistema capitalista, regidos por uma nova ordem globalizante.

Identificar potencialidades naturais, em nível local ou regional, se constitui em uma forma de contribuição da ciência geográfica para subsidiar tanto o estado, como o setor produtivo, uma vez que esta ciência tem abordagem holística da relação entre sociedade e natureza.

\section{REFERÊNCIAS}

ANDRADE, M. C. de. O território do sal. Mossoró: Coleção Mossoroense, 1995.

CARVALHO JÚNIOR, J. V.; FELIPE, J. L. A.; ESCÓSSIA, C. A. Introdução à história do sal. Terra e Sal, Mossoró, ano 1, n.2, p. 6-26, dez. 1982.

BARBIÉRI, E. B. Ritmo climático e extração do sal em Cabo Frio. Tese de Mestrado apresentada ao Departamento de Geografia da Faculdade de Filosofia, Letras e Ciências Humanas da Universidade de São Paulo Separata da Revista Brasileira de Geografia, ano 37, $\mathrm{n}^{\circ}$ 4. IBGE, 1975.

BARROS, L. F. F.; SANTOS. Aplicação de Técnicas de Geoprocessamento para fins de Análise da Expansão da Salinocultura/Carcinicultura no Estuário de Rio Piranhas-Açu/RN, no Período de 1989 a 2009. In: Reunião Anual da Sociedade Brasileira para o Progresso da Ciência, 62, 2010, Natal. Livro eletrônico Anais... São Paulo: SBPC, 2010. Disponível em: <http://www.sbpcnet.org.br/livro/62ra/resumos/ resumos/1940.htm>. Acesso em: 08 mai. de 2013.

BRASIL. Departamento Nacional de Produção Mineral - DNPM. Sumário Mineral. Brasília: DNPM/ DIPLAM, 1997.

BRASIL. Sumário Mineral. Brasília: DNPM/ DIPLAM, 1998.

BRASIL. Sumário Mineral. Brasília: DNPM/ DIPLAM, 1999. 
BRASIL. Sumário Mineral. Brasília: DNPM/ DIPLAM, 2000.

BRASIL. Sumário Mineral. Brasília: DNPM/ DIPLAM, 2001.

BRASIL. Sumário Mineral. Brasília: DNPM/ DIPLAM, 2002.

BRASIL. Sumário Mineral. Brasília: DNPM/ DIPLAM, 2003.

BRASIL. Sumário Mineral. Brasília: DNPM/ DIPLAM, 2004.

BRASIL. Anuário Mineral Brasileiro. Brasília: DNPM, 2004.

BRASIL. Sumário Mineral. Brasília: DNPM/ DIPLAM, 2005.

BRASIL. Sumário Mineral. Brasília: DNPM/ DIPLAM, 2006.

BRASIL. Sumário Mineral. Brasília: DNPM/ DIPLAM, 2007.

BRASIL. Sumário Mineral. Brasília: DNPM/ DIPLAM, 2008.

BRASIL. Sumário Mineral. Brasília: DNPM/ DIPLAM, 2009.

BRASIL. Sumário Mineral. Brasília: DNPM/ DIPLAM, 2010.

BRASIL. Sumário Mineral. Brasília: DNPM/ DIPLAM, 2011.

BRASIL. Instituto Brasileiro de Geografia e Estatística - IBGE. Anuário Estatístico do Brasil 1941/1945. Rio de Janeiro: IBGE, 1945.

BRASIL. Anuário Estatístico do Brasil 1941/1945. Rio de Janeiro: IBGE, V.6, 1946.
BRASIL. Anuário Estatístico do Brasil 1946. Rio de Janeiro: IBGE, V.7, 1947.

BRASIL. Anuário Estatístico do Brasil 1947. Rio de Janeiro: IBGE, V.8, 1948.

BRASIL. Anuário Estatístico do Brasil 1948. Rio de Janeiro: IBGE, V.9, 1949.

BRASIL. Anuário Estatístico do Brasil 1949. Rio de Janeiro: IBGE, V.10, 1950.

BRASIL. Anuário Estatístico do Brasil 1950. Rio de Janeiro: IBGE, V.11, 1951.

BRASIL. Anuário Estatístico do Brasil 1951. Rio de Janeiro: IBGE, V.12, 1952.

BRASIL. Anuário Estatístico do Brasil 1952. Rio de Janeiro: IBGE, V.13, 1953.

BRASIL. Anuário Estatístico do Brasil 1953. Rio de Janeiro: IBGE, V.14, 1953.

BRASIL. Anuário Estatístico do Brasil 1954. Rio de Janeiro: IBGE, V.15, 1954.

BRASIL. Anuário Estatístico do Brasil 1955. Rio de Janeiro: IBGE, V.16, 1955.

BRASIL. Anuário Estatístico do Brasil 1956. Rio de Janeiro: IBGE, V.17, 1956.

BRASIL. Anuário Estatístico do Brasil 1957. Rio de Janeiro: IBGE, V.18, 1957.

BRASIL. Anuário Estatístico do Brasil 1958. Rio de Janeiro: IBGE, V.19, 1958.

BRASIL. Anuário Estatístico do Brasil 1959. Rio de Janeiro: IBGE, V.20, 1959.

BRASIL. Anuário Estatístico do Brasil 1960. Rio de Janeiro: IBGE, V.21, 1960.

BRASIL. Anuário Estatístico do Brasil 1961. Rio de 
Janeiro: IBGE, V.22, 1961.

BRASIL. Anuário Estatístico do Brasil 1962. Rio de Janeiro: IBGE, V.23, 1962.

BRASIL. Anuário Estatístico do Brasil 1963. Rio de Janeiro: IBGE, V.24, 1963.

BRASIL. Anuário Estatístico do Brasil 1964. Rio de Janeiro: IBGE, V.25, 1964.

BRASIL. Anuário Estatístico do Brasil 1965. Rio de Janeiro: IBGE, V.26, 1965.

BRASIL. Anuário Estatístico do Brasil 1966. Rio de Janeiro: IBGE, V.27, 1966.

BRASIL. Anuário Estatístico do Brasil 1967. Rio de Janeiro: IBGE, V.28, 1967.

BRASIL. Anuário Estatístico do Brasil 1968. Rio de Janeiro: IBGE, V.29, 1968.

BRASIL. Anuário Estatístico do Brasil 1969. Rio de Janeiro: IBGE, V.30, 1969.

BRASIL. Anuário Estatístico do Brasil 1970. Rio de Janeiro: IBGE, V.31, 1970.

BRASIL. Anuário Estatístico do Brasil 1971. Rio de Janeiro: IBGE, V.32, 1971.

BRASIL. Anuário Estatístico do Brasil 1972. Rio de Janeiro: IBGE, V.33, 1972.

BRASIL. Anuário Estatístico do Brasil 1973. Rio de Janeiro: IBGE, V.34, 1973.

BRASIL. Anuário Estatístico do Brasil 1974. Rio de Janeiro: IBGE, V.35, 1974.

BRASIL. Anuário Estatístico do Brasil 1975. Rio de Janeiro: IBGE, V.36, 1975.

BRASIL. Anuário Estatístico do Brasil 1976. Rio de Janeiro: IBGE, V.37, 1976.
BRASIL. Anuário Estatístico do Brasil 1977. Rio de Janeiro: IBGE, V.38, 1977.

BRASIL. Anuário Estatístico do Brasil 1978. Rio de Janeiro: IBGE, V.39, 1978.

BRASIL. Anuário Estatístico do Brasil 1979. Rio de Janeiro: IBGE, V.40, 1979.

BRASIL. Anuário Estatístico do Brasil 1980. Rio de Janeiro: IBGE, V.41, 1980.

BRASIL. Anuário Estatístico do Brasil 1981. Rio de Janeiro: IBGE, V.42, 1981.

BRASIL. Anuário Estatístico do Brasil 1982. Rio de Janeiro: IBGE, V.43, 1982.

BRASIL. Anuário Estatístico do Brasil 1983. Rio de Janeiro: IBGE, V.44, 1983.

BRASIL. Anuário Estatístico do Brasil 1984. Rio de Janeiro: IBGE, V.45, 1984.

BRASIL. Anuário Estatístico do Brasil 1985. Rio de Janeiro: IBGE, V.46, 1985.

BRASIL. Anuário Estatístico do Brasil 1986. Rio de Janeiro: IBGE, V.47, 1986.

BRASIL. Anuário Estatístico do Brasil 1987/1988. Rio de Janeiro: IBGE, V.48, 1988.

BRASIL. Anuário Estatístico do Brasil 1989. Rio de Janeiro: IBGE, V.49, 1989.

BRASIL. Anuário Estatístico do Brasil 1990. Rio de Janeiro: IBGE, V.50, 1990.

BRASIL. Anuário Estatístico do Brasil 1991. Rio de Janeiro: IBGE, V.51, 1991.

BRASIL. Anuário Estatístico do Brasil 1992. Rio de Janeiro: IBGE, V.52, 1992. 
BRASIL. Anuário Estatístico do Brasil 1993. Rio de Janeiro: IBGE, V.53, 1993.

BRASIL. Anuário Estatístico do Brasil 1994. Rio de Janeiro: IBGE, V.54, 1994.

BRASIL. Anuário Estatístico do Brasil 1995. Rio de Janeiro: IBGE, V.55, 1995.

BRASIL. Anuário Estatístico do Brasil 1996. Rio de Janeiro: IBGE, V.56, 1996.

BRASIL. Anuário Estatístico do Brasil 1997. Rio de Janeiro: IBGE, V.57, 1997.

BRASIL, M. V. de O.; NOGUEIRA, C. A. G.; FORTE, S. H. A. C. Schumpeter e o Desenvolvimento Tecnológico: uma visão aplicada às Pequenas e Médias Empresas (PMEs). Revista de ciências da administração, v. 13, n. 29, p. 38-62, jan, 2011. DOI: 10.5007/2175-8077.2011v13n29p38

CARMO JÚNIOR, J. B. Geografia da dominação: um estudo sobre a organização espacial da terra do sal (Macau-RN). Natal, 2006. 172f. Dissertação (Mestrado). Programa de Pós-graduação em Arquitetura e Urbanismo, Universidade Federal do Rio Grande do Norte. Centro de Tecnologia, NatalRN, 2006.

CHRISTÓVÃO, J. H. de O. Do sal ao sol: a construção social da imagem do turismo em Cabo Frio. São Gonçalo, 2011. 145f. Dissertação (Mestrado em História Social). Programa de Pós-Graduação em História Social, Universidade do Estado do Rio de Janeiro, São Gonçalo-RJ, 2011.

CONSTREMAC Construções, 2010. Disponível em: $<$ http://www.constremac.com.br/newsletterContent. aspx? codigo $=83>$. Acesso em: 18 nov. 2015

DINIZ, M. T. M. Bases para um plano de gestão integrada de zonas costeiras em Jacaúna - Aquiraz - CE. Fortaleza, 2008. 137f. Dissertação de Mestrado. Programa de Pós-graduação em Geografia, Universidade Estadual do Ceará - UECE, Fortaleza, 2008.
DNPM. Departamento Nacional de Produção Mineral. Sumário Mineral. Brasília: DNPM/DIPLAM, 1997.

FEMENICK, T. O sal nosso de cada dia IV: Pesadelos e sonhos portuários. Gazeta do Oeste, Mossoró, 14 out. 2007. Disponível em <www.tomislav.com. br/o-sal-nosso-de-cada-dia-iv-pesadelo-e-sonhosportuarios/>. Acesso em: 12 mar. 2013.

GIFFONI, José Marcello Salles. Sal: um outro império (1801-1850). Niterói, 1999. Dissertação (Mestrado em História). Programa de Pós-Graduação em História, Universidade Federal Fluminense, Niterói-RJ, 1999.

PIRES, H. F. Estruturas virtuais de acumulação e cibercidades: das estruturas territoriais às estruturas virtuais de acumulação no capitalismo contemporâneo. Scripta Nova, Vol. VIII, núm. 170 (59), ago. 2004. Disponível em $<$ http://www.ub.edu/geocrit/sn/sn-17059.htm>. Acesso em: 08 mar. 2012.

SCHUMPETER, J. A. Capitalismo, socialismo e democracia. Editado por George Allen e UnwinLtd. Tradução Ruy Jungmann. Rio de Janeiro: Editora Fundo de Cultura, 1961. Edição online de Ordemlivre. org. Disponível em: <http://www.ordemlivre. org/2011/08/joseph-schumpeter-capitalismosocialismo-e-democracia/>. Acesso em: 08 de março de 2012.

SCHUMPETER, J. A. Teoria do desenvolvimento econômico: uma investigação sobre lucros, capital, crédito, juro e o ciclo econômico. Tradução Maria Sílvia Possas. São Paulo: Editora Nova Cultural. 1997. Título original: Theorie der WirtschaftlichenEntwicklung. Dunker\&Humblot, Berlim, Alemanha, 1964.

SOUTO, E. F.; FERNANDES, C. H. C. A importância da indústria salineira do Rio Grande do Norte para a economia brasileira. Mossoró: Coleção Mossoroense, 2005. 